\title{
Amyotrophic lateral sclerosis presenting as typical split hand syndrome
}

\author{
Murali Nalabothu, ${ }^{1}$ Naresh Monigari, ${ }^{1}$ Nagapriya Vellalacheruvu, ${ }^{1}$ \\ Jyosthna Elagandula ${ }^{2}$
}

${ }^{1}$ Department of Medicine, Kasturba Medical College, Manipal, Karnataka, India ${ }^{2}$ Department of Radiation Oncology, MS Ramaiah Medical College, Bangalore, Karnataka, India

\section{Correspondence to} Dr Naresh Monigari, medico.ktya@gmail.com

Accepted 5 October 2014
CrossMark

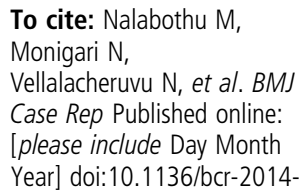

\section{DESCRIPTION}

A 38-year-old man presented to a hospital with weakness of both hands (right $>$ left) with associated generalised weakness for the past 2 years. The patient initially noticed weakness and thinning of his right hand followed by the left for 2 years, then he noticed a thinning of the arms, right more so that left, and his right thigh for the past 6 months. General examination showed flattening over the right shoulder and wasting of the thenar eminence on both hands with normal hypothenar muscles (figures 1 and 2). Nervous system examination showed tongue fasciculations and significant asymmetrical wasting of abductor pollicis brevis (APB), and first dorsal interossei (FDI) with sparing of abductor digiti minimi (ADM) was noted (figures 1 and 2), but strength was normal in all four limbs with the exception of bilateral weak pincer grip. The patient had wasting of both arms (circumference $10 \mathrm{~cm}$ above the olecranon process was 18 and $21 \mathrm{~cm}$ for the right and left arms, respectively) and right thigh (circumference $10 \mathrm{~cm}$ above tibial tuberosity was $35 \mathrm{~cm}$ with left side being $40 \mathrm{~cm}$ ). The patient had exaggerated reflexes in all four limbs with flexor plantar response and fasciculations most noticeably in deltoid, pectoral and quadriceps muscles suggesting definitive diagnosis of amyotrophic lateral sclerosis (ALS) by EL Escorial criteria. Other cranial nerves, motor, sensory and

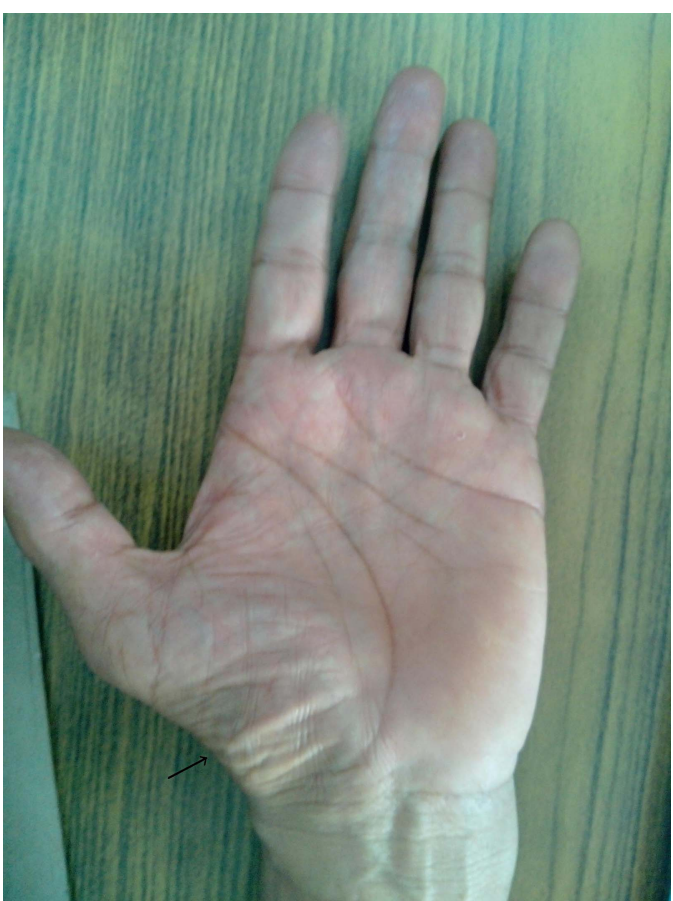

Figure 1 Atrophy of thenar muscles (arrow).

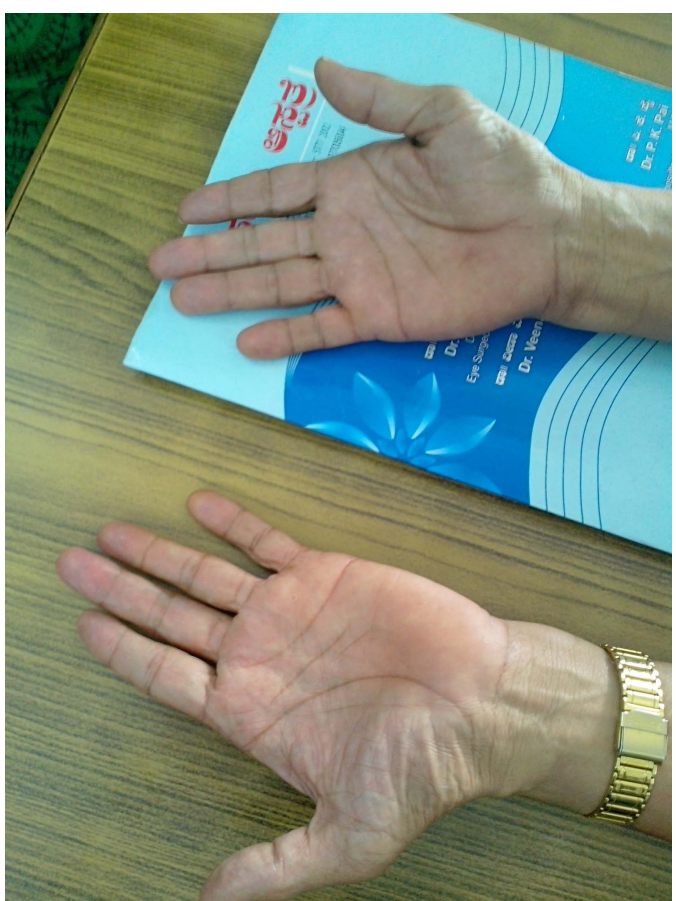

Figure 2 Both hands with split hand syndrome in the patient with amyotrophic lateral sclerosis.

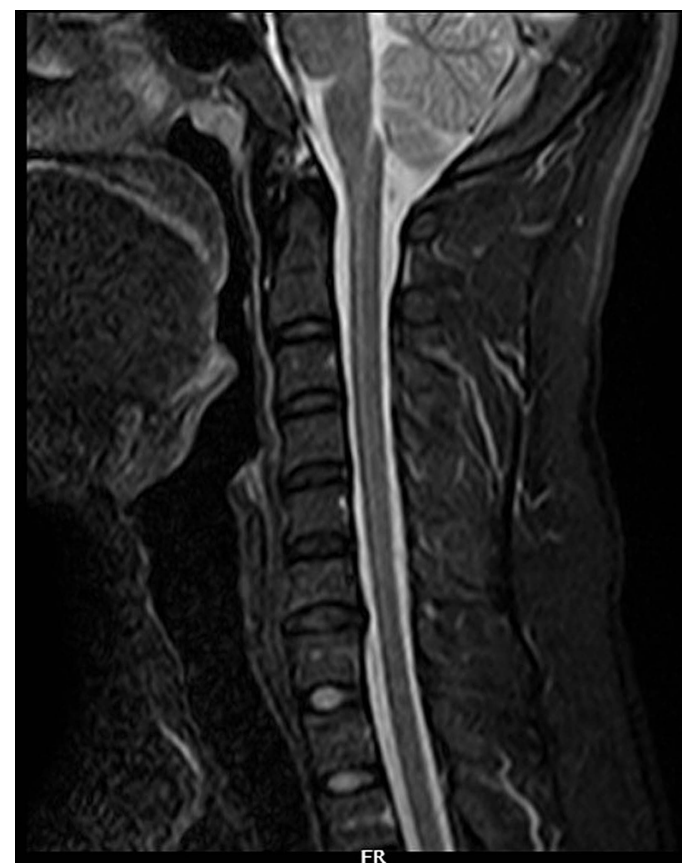

Figure 3 MRI T2 cervical spine sagittal view showing mild dehydrative disc changes with normal spinal cord. 
cerebellar examinations were within normal limits. MRI of the brain and cervical spine were normal, ruling out cervical myelopathy and cervicovertebral junction abnormality (figure 3). Nerve conduction velocity showed compound motor action potential recorded in APB (median nerve at wrist) to be $4.3 \mathrm{mV}$ and ADM (ulnar nerve at wrist) to be $5.0 \mathrm{mV}$ with ratio $<1$, suggestive of split hand phenomenon of ALS, normal sensory nerve action potential and normal F-wave latency in bilateral median, ulnar and femoral nerves, ruling out the possibility of multifocal motor neuropathy with conduction block. Although hyperexcitability of APB was thought to be a cause for preferential wasting, this was not observed in our patient. ${ }^{1}$ Electromyography showed evidence of active denervation with fibrillation and fasciculation potentials in bilateral APB, FDI, deltoid and quadriceps muscles. The reason for differential involvement of hand muscles with wasting of thenar muscles (APB and FDI) and sparing of hypothenar muscles (ADM), both supplied by C8-T1 nerve roots, is unclear. Split hand syndrome can be useful to suspect a diagnosis of ALS. As per the latest evidence, cortical and peripheral mechanisms have a role in development of the syndrome. ${ }^{2}$ That even greater use of the thenar group of muscles would have led to more oxidative stress within them leading to preferential damage may also be a possibility. $^{2}$ The patient was treated with riluzole $50 \mathrm{mg}$ orally twice a day but did not show much improvement on review after 3 years.

\section{Learning points}

- Split hand syndrome is a very rare entity and may be the only manifestation in early amyotrophic lateral sclerosis (ALS) with high specificity.

- As there is no definitive therapy for ALS all other possible causes have to be ruled out before diagnosis of ALS.

Contributors NM and MN drafted the article and reviewed the literature. JE and NV critically reviewed the article prior to submission.

Competing interests None.

Patient consent Obtained.

Provenance and peer review Not commissioned; externally peer reviewed.

\section{REFERENCES}

1 Shibuya K, Misawa S, Nasu S, et al. Split hand syndrome in amyotrophic lateral sclerosis: different excitability changes in the thenar and hypothenar motor axons. J Neurol Neurosurg Psychiatry 2013;84:969-72.

2 Eisen A, Kuwabara S. The split hand syndrome in amyotrophic lateral sclerosis. J Neurol Neurosurg Psychiatry 2012;83:399-403.

\footnotetext{
Copyright 2014 BMJ Publishing Group. All rights reserved. For permission to reuse any of this content visit http://group.bmj.com/group/rights-licensing/permissions.

BMJ Case Report Fellows may re-use this article for personal use and teaching without any further permission.

Become a Fellow of BMJ Case Reports today and you can:

- Submit as many cases as you like

- Enjoy fast sympathetic peer review and rapid publication of accepted articles

- Access all the published articles

- Re-use any of the published material for personal use and teaching without further permission

For information on Institutional Fellowships contact consortiasales@bmjgroup.com

Visit casereports.bmj.com for more articles like this and to become a Fellow
} 